\title{
Modulation of Nr-13 antideath activity by peptide aptamers
}

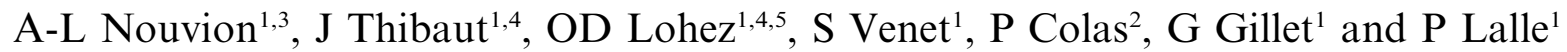 \\ ${ }^{1}$ Equipe Apoptose et Oncogenèse, Institut de Biologie et Chimie des Protéines (IBCP UMR 5086 CNRS/Université claude Bernard \\ Lyon 1), IFR128 BioSciences Lyon-Gerland, Lyon, France and '2Aptanomics SA, 181-203 avenue Jean Jaurès, F-69007 Lyon, France
}

\begin{abstract}
Tumor cells are characterized by deregulated proliferation and resistance to proapoptotic stimuli. The Bcl-2 family of antiapoptotic proteins is overexpressed in a large number of chemoresistant tumors. Downregulation or inhibition of antiapoptotic proteins might result in the sensitization of cancer cells to chemotherapeutic agents. In the present study, we took advantage of the peptide aptamer strategy to target $\mathrm{Nr}-13$, a Bcl-2 antiapoptotic protein involved in neoplastic transformation by the Rous sarcoma virus. We isolated peptide aptamers that behave as $\mathrm{Nr}-13$ regulators, in vitro and in mammalian cells in culture. Some of these aptamers have potential proapoptotic activities. These data suggest that peptide aptamers targeting the Bcl-2 family of apoptosis inhibitors may be useful for the development of anticancer molecules.
\end{abstract}

Oncogene (2007) 26, 701-710. doi:10.1038/sj.onc.1209832; published online 14 August 2006

Keywords: $\mathrm{Bcl}-2$; $\mathrm{Nr}-13$; peptide aptamer; apoptosis; ligand

\section{Introduction}

A number of tumor cells are characterized by deregulated proliferation and resistance to proapoptotic stimuli, including chemotherapeutic agents (Hanahan and Weinberg, 2000). Strategies aimed at sensitizing tumors to anticancer treatments are thus of critical importance. Proteins that are overexpressed or structurally affected in cancers could conceivably be promising drug targets. Indeed, overexpression of $b c l$-2-related genes is often correlated with chemoresistant phenotypes, including multidrug resistance (Pommier et al.,

Correspondence: Professor G Gillet, Equipe Apoptose et Oncogenèse, Institut de Biologie et Chimie des Protéines (IBCP UMR 5086 CNRS Université Claude Bernard Lyon 1), IFR128 BioSciences LyonGerland, 7 passage du Vercors, F-69367 Lyon Cedex 07, France.

E-mail: g.gillet@ibcp.fr

${ }^{3}$ Current address: McGill University, McIntyre Medical Sciences Building, 3655 promenade Sir-William-Osler, Montréal, Québec, Canada.

${ }^{4}$ These authors contributed equally to this work.

${ }^{5}$ Current address: UMR 5161 CNRS-ENS Lyon, IFR128 BioSciences Lyon-Gerland, Lyon, France.

Received 28 October 2005; revised 30 May 2006; accepted 9 June 2006; published online 14 August 2006
2004). The Bcl-2 family of proteins is a key regulator of apoptosis, determining cell fate in response to developmental cues and various stress signals (Cory et al., 2003). Various approaches are being used to inactivate these proteins in tumor cells, for example, antisense oligonucleotides (Cotter et al., 1999), small synthetic inhibitors obtained from computer-based or functional screening of libraries (Wang et al., 2000; Jiang et al., 2003; Oltersdorf et al., 2005) or peptides mimicking the $\mathrm{BH} 3$ domain of apoptosis accelerators (Degterev et al., 2001; Walensky et al., 2004). Clinical trials are currently underway with a number of these potential new anticancer agents (Reed, 2003; Juin et al., 2004).

Peptide aptamers are a powerful technology to isolate specific inhibitors against intracellular targets. They are made of short peptides of random sequences presented into a scaffold protein, which constrains their conformation. The most widely used platform protein is the bacterial thioredoxin A (TrxA). A number of peptide aptamers have been isolated, which act as inhibitors of proteins involved in human cancers such as the cell cycle regulator cyclin-dependent kinase $(\mathrm{Cdk}) 2$ (Colas et al., 1996), the transcription factor E2F (Fabbrizio et al., 1999), the G-protein Ras (Kurtz et al., 2003), the epidermal growth factor (EGF) receptor (Buerger et al., 2003) and transforming growth factor- $\beta$ (Cui et al., 2005). Two studies have shown an induction of apoptosis in cancer cells by peptide aptamers targeting the E6 and E7 papillomavirus oncoproteins (Butz et al., 2000; Nauenburg et al., 2001). To our knowledge, peptide aptamers have not yet been isolated against apoptosis regulators of the $\mathrm{Bcl}-2$ family.

The chicken Nr-13 protein is a member of the Bcl-2 family of apoptosis inhibitors. Nr-13 and orthologous genes (zebrafish $n r z$, murine boo/diva and human $n r h$ ), together with $m c l-1$ and $b f l-1$, belong to a subgroup among the antiapoptotic genes (Lanave et al., 2004). Like Bcl-2 and related death inhibitors, $\mathrm{Nr}-13$ inhibits apoptosis at least in part via heterodimerization with the death accelerator Bax (Lalle et al., 2002; Girard-Egrot et al., 2004). There is evidence that $\mathrm{Nr}-13$ plays a role in cells infected by the Rous sarcoma virus (Mangeney et al., 1996; Aouacheria et al., 2002). This raises the possibility that the inactivation of the $\mathrm{Nr}-13$ protein may impair tumor progression.

In this report, we present the characterization of peptide aptamers raised against the $\mathrm{Nr}-13$ protein. One of these aptamers is able to bind the $\mathrm{N}$ terminus of the 
protein, whereas the other binds the more conserved C-terminal moiety. To evaluate their effects on $\mathrm{Nr}-13$ activity, first we co-transfected plasmid constructs encoding peptide aptamers together with $\mathrm{Nr}-13$ expression vectors into yeast or mammalian cells. Second, we tested the effect of synthetic peptides corresponding to the variable sequence of the aptamers using an in vitro caspase assay. We show that one of the aptamers is a potent inhibitor of $\mathrm{Nr}-13$, whereas the other one behaves as an agonist of $\mathrm{Nr}-13$. Our data show for the first time that peptide aptamers can modulate the antideath activity of a Bcl-2 protein, either negatively or positively. Interestingly, these aptamers do not share sequence homology with any of the BH3-derived peptides known to target the typical hydrophobic cleft found in Bcl-2 family members, which have been used to date to isolate Bcl-2 antagonists.

\section{Results}

Isolation of peptide aptamers specifically interacting with the $\mathrm{Nr}-13$ protein

In order to isolate peptide aptamers that specifically bind the Nr-13 protein, a yeast two-hybrid screen was performed as described previously (Colas et al., 1996). $\mathrm{Nr}-13$ belongs to a large family of apoptosis regulators sharing homology domains in the C-terminal moiety, including the conserved hydrophobic cleft, which is the binding site for $\mathrm{BH} 3$ peptides and related molecules (Juin et al., 2004). Thus, in order to maximize the chances of obtaining specific Nr-13 ligands, we focused on the N-terminal moiety of $\mathrm{Nr}-13$ that shows poor homology with other Bcl-2-related proteins (Lalle et al., 2002). The first 63 amino acids of $\mathrm{Nr}-13$, comprising the $\mathrm{BH} 4$ and $\mathrm{BH} 3$ domains, fused to the LexA protein served as bait (in the pGILDA vector). As prey constructs, we used the pJM1 vector to express a library in which 20-mer peptides of randomized sequence were inserted into the active loop of the Escherichia coli TrxA. The interaction screen was performed using the EGY48 strain co-transfected with the two constructs and the reporter plasmid pSH18-34. The screening of $2 \times 10^{6}$ transfected yeasts led to the isolation of 51 transformants. One of them, named C6-14, was confirmed after rescuing, retransformation of the plasmids and reselection.
A simultaneous two-hybrid screen directed against the murine Bax protein ( $\mathrm{P}$ Colas, unpublished data) allowed us to isolate another peptide aptamer, B16, able to target both Bax and the C-terminal moiety of $\mathrm{Nr}-13$. Random mutagenesis was performed on C6-14 and B16 to isolate derivatives with higher affinity for $\mathrm{Nr}-13$. Random mutagenesis of C6-14 led to the isolation of $\mathrm{M} 10 \mathrm{~b} 1$ and M2a2, the latter no longer able to recognize Nr-13. B16 derivative B16m3 lost its Bax binding capacity but still recognized $\mathrm{Nr}-13$, whereas B16m39 no longer bound Bax or Nr-13 (Table 1 and Figure 1).

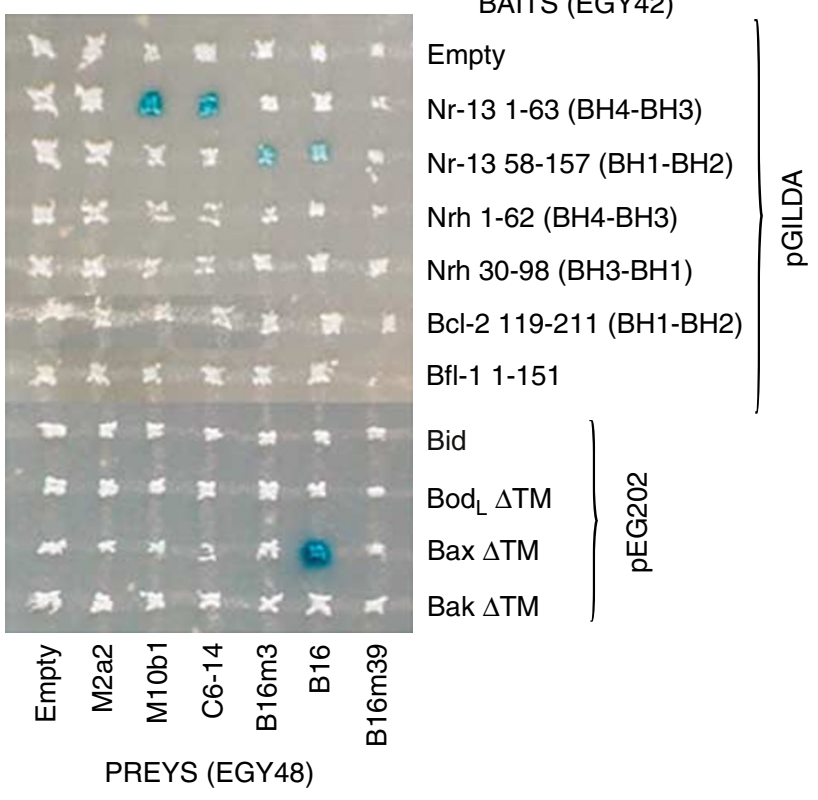

Figure 1 Interaction matrix of $\mathrm{Nr}-13$ and $\mathrm{Bcl}-2$ family members with peptide aptamers in yeast. Yeast clones expressing various truncations of Nr-13, Nrh, Bcl-2 (human), Bfl-1 (human), BodL (rat), Bax (mouse), Bak (human) and full-length Bid (mouse) in bait vectors pGILDA or pEG202 were mated with clones expressing peptide aptamers in prey vector pJG4-5. An interaction matrix picture was taken after $48 \mathrm{~h}$ incubation at $30^{\circ} \mathrm{C}$. Aptamers M10b1 and C6-14 interact specifically with the 1-63 amino-acid region of $\mathrm{Nr}-13$ (containing the $\mathrm{BH} 4$ and $\mathrm{BH} 3$ domains of $\mathrm{Nr}-13$ ), but not with the other truncations of $\mathrm{Nr}-13$ or other $\mathrm{Bcl}-2$ family members. B16 aptamer interacts with Bax, whereas its derivative $\mathrm{B} 16 \mathrm{~m} 3$ interacts with the $58-157$ amino-acid region of $\mathrm{Nr}-13$ (containing the $\mathrm{BH} 1$ and $\mathrm{BH} 2$ domains of $\mathrm{Nr}-13$ ). Another $\mathrm{B} 16$ derivative, $\mathrm{B} 16 \mathrm{~m} 39$, lost the ability to interact with both Bax and $\mathrm{Nr}-13$. Expression of the different proteins was checked by Western blotting (not shown).

Table 1 Sequences of peptide aptamers

\begin{tabular}{|c|c|c|c|c|}
\hline Aptamer & Isolated by & $\mathrm{Nr}-13$ binding & Bax binding & Sequence of the variable region \\
\hline C6-14 & Anti-chicken $\mathrm{Nr}-13$ screening & + & - & TrxA - RRGSPVLEASKAVDVLFLVL - TrxA \\
\hline M10b1 & C6-14 mutagenesis & + & - & TrxA - RRGSPVMEASKAVDVLFLAL - TrxA \\
\hline M2a2 & C6-14 mutagenesis & - & - & TrxA - RRGSPVLEASRAVDVSFLVL - TrxA \\
\hline B16 & Anti-murine Bax screening & + & + & TrxA - PRGAPMWMRWVCQMLETMFL - TrxA \\
\hline $\mathrm{B} 16 \mathrm{~m} 3$ & B16 mutagenesis & + & - & TrxA - PRGAPLWLCWVWQMLETMLP - TrxA \\
\hline B16m39 & B16 mutagenesis & - & - & TrxA - PWVAPMRMRRVRLMLETMFL - TrxA \\
\hline
\end{tabular}

Abbreviation: TrxA, thioredoxin A. 
BLAST searches did not reveal sequence similarities between any of these peptides and known proteins.

To confirm the specificity of the interaction with $\mathrm{Nr}-13$, we used an interaction mating assay (Finley and Brent, 1994) with different bait constructs, including both pro- and antiapoptotic members of the Bcl-2 family. Expression of all proteins was checked using an anti-LexA antibody and was found equivalent. $\mathrm{Nr}-13$ was the only protein recognized by B16m3, C6-14 and its derivative M10b1 among a series of Bcl-2 family members (Figure 1). M10b1 harbors a slightly stronger blue coloration than C6-14 (Figure 1). In addition, this coloration is detected significantly earlier than in C6-14 colonies (not shown), suggesting a higher affinity for $\mathrm{Nr}$-13. In summary, these aptamers recognize different regions of $\mathrm{Nr}-13$. B16m 3 binds the C-terminal moiety, containing the conserved $\mathrm{BH} 1$ and $\mathrm{BH} 2$ domains, whereas C6-14 and its derivative M10b1 recognize the $\mathrm{N}$ terminus moiety.

Interactions of the selected peptide aptamers were confirmed using co-immunoprecipitations. Different Bcl-2 proteins were overexpressed in COS-7 cells transiently transfected with the pSG5-FLAG vector. Cell lysates were incubated with purified aptamers, followed by immunoprecipitation using anti-FLAG antibody. The presence of the aptamer in the immunoprecipitates was analysed by Western blotting with an anti-TrxA antibody (Figure 2a). Significant binding was observed between $\mathrm{Nr}-13$ and $\mathrm{C} 6-14$ (not shown) or M10b1, but not with TrxA (not shown) or the negative control M2a2. The other Bcl-2 proteins used in this experiment do not bind M10b1 under these conditions. These observations perfectly matched the yeast twohybrid results (Figure 1). Together, these data indicate that the selected peptide aptamers that specifically interact with $\mathrm{Nr}-13$ in vivo in yeast also interact with $\mathrm{Nr}-13$ in vitro. This rules out the possibility of nonspecific interactions mediated by an endogenous third protein in yeast.

An enzyme-linked immunosorbent assay (ELISA)binding assay demonstrated that fluid-phase aptamers bound to recombinant $\mathrm{Nr}-13$ that was passively adsorbed to wells of a microtitration plate. After washing such coated plates, aptamers were added in incremental amounts and the extent of binding was quantified by the sequential addition of anti-TrxAperoxidase-conjugated antibody. Binding was expressed as the enzymatic activity of the bound peroxidase $\left(\Delta A_{405 \mathrm{~nm}}\right)$ (see Figure 2c). Complex formation was saturable with estimated apparent $K_{\mathrm{D}}$ of $0.2 \mu \mathrm{M}$ (B16m3) and $4.5 \mu \mathrm{M}$ (M10b1). By comparison, BH3 peptides typically bind to the prosurvival proteins with $K_{\mathrm{D}}$ of 5-100 nM (Chen et al., 2005).

\section{Peptide aptamers interfere with $\mathrm{Nr}$-13 antideath activity in yeast}

We previously showed that $\mathrm{Nr}-13$ behaves as an antiBax protein (Lalle et al., 2002). In particular, we showed that $\mathrm{Nr}-13$ efficiently counteracts Bax cytotoxicity in yeast. We thus tested the ability of the peptide aptamers

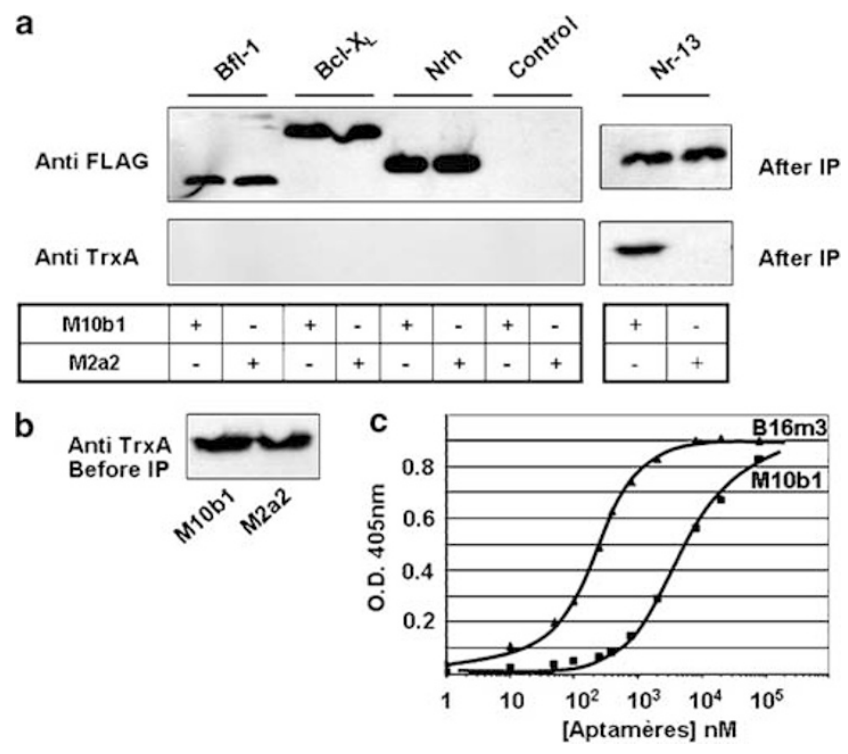

Figure 2 Confirmation and characterization of $\mathrm{Nr}-13$ peptide aptamers binding. (a) The interaction of peptide aptamers with four antiapoptotic proteins was checked by co-immunoprecipitation experiments using recombinant proteins. Purified peptide aptamers M10b1 and M2a2 were incubated with COS-7 cell extracts overexpressing or not the FLAG-tagged antiapoptotic proteins, and then immunoprecipitated using anti-FLAG antibody. Immunocomplexes were analysed by Western blotting using antiTrxA and anti-FLAG antibodies. M10b1 but not M2a2 interacts with $\mathrm{Nr}-13$, whereas no interaction is detected with the three other Bcl-2 family members, thus confirming the specificity of the interaction found in the two-hybrid experiments. (b) Analysis of samples before immunoprecipitation. Western blots were revealed with anti-TrxA antibody, showing that the two peptide aptamers were present in equivalent amounts before immunoprecipitation. (c) Concentration dependence of the Nr-13/aptamer interaction determined in an ELISA-style ligand binding assay. Different concentrations of $\mathrm{M} 10 \mathrm{~b} 1$ or $\mathrm{B} 16 \mathrm{~m} 3$ were incubated with $6 \mathrm{His}-\mathrm{Nr}$ 13- $\Delta$ TM-6His coated onto a 96-well plate. Binding was detected in an ELISA-style manner using an antibody directed against the TrxA scaffold. Intensity of the signal obtained with TrxA used as a negative control was subtracted from each experimental point.

to modulate $\mathrm{Nr}-13$ activity in this model (Figure 3). As expected, control aptamers M2a2 and $\mathrm{B} 16 \mathrm{~m} 39$ did not alter the inhibitory effect of $\mathrm{Nr}-13$ on Bax-induced cell death (data not shown), whereas in contrast, C6-14 and M10b1 significantly reduced the growth rate of transfected yeasts, suggesting that these latter aptamers actually inhibited Nr-13 anti-Bax activity. M10b1 exhibited the strongest effect as expected by the apparent higher affinity observed in the two-hybrid assay. C6-14 and M10b1 did not affect Bax-induced cell death in the absence of Nr-13. The third aptamer, B16m3, showed no effect in this system (not shown).

\section{Peptide aptamers modulate cell death in vertebrates} Co-transfection experiments were carried out to assess the biological activity of the most efficient antagonist aptamer (M10b1) in mammalian cells. Plasmid constructs expressing aptamers and $\mathrm{Nr}-13$ or Bcl-xL proteins were transiently transfected in COS-7 cells. The two C6-14 derivatives M10b1 and M2a2 were 


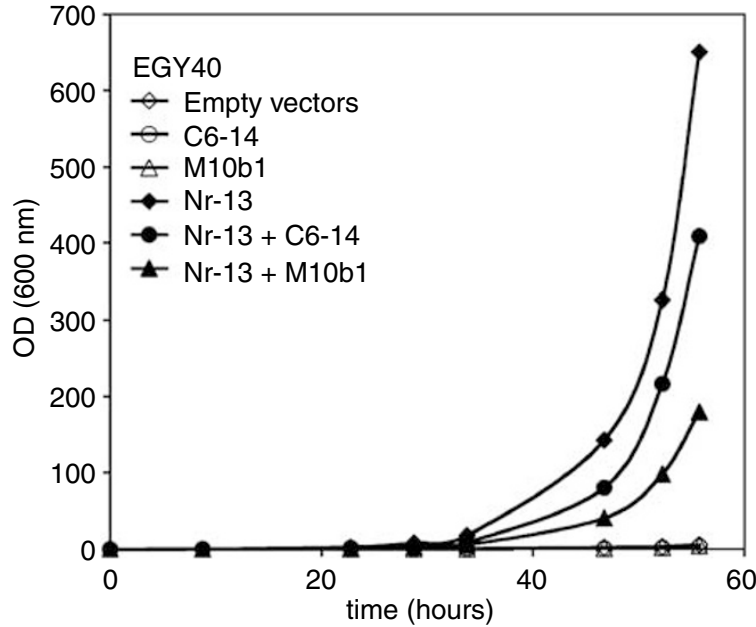

Figure 3 Effect of peptide aptamers on $\mathrm{Nr}-13$ activity. The EGY40 strain was co-transformed with pGILDA-Bax and pJG4-5 (with or without $\mathrm{Nr}-13$ ) vectors. In this system, aptamers were expressed using the pBC103 vector (Sun et al., 1997). After overnight growth in the presence of glucose, yeast cells were cultured in the presence of $2 \%$ galactose to induce the expression of Bax alone (empty vectors) or together with $\mathrm{Nr}-13$ and/or the indicated aptamer. Bax totally abolishes yeast growth (open diamonds); this effect is prevented by Nr-13 (black diamonds). C6-14 (black circles) and M10b1 (black triangles) aptamers behave as inhibitors of Nr-13. In the absence of Nr-13, C6-14 (open circles) or M10b1 (open triangles) have no effect on Bax activity. Expression of $\mathrm{B} 16 \mathrm{~m} 3$ does not affect yeast growth, whether or not $\mathrm{Nr}-13$ is expressed or not (curves are not shown for clarity).

expressed as green fluorescence protein (GFP) fusions so that their expression could be easily monitored by fluorescence (not shown). $\mathrm{Nr}-13$ and $\mathrm{Bcl}-\mathrm{xL}$ were expressed as FLAG-tagged recombinant proteins. Expression of the proteins of interest was checked by Western blotting (Figure 4a). Eight hours after transfection, serum was withdrawn to induce apoptosis. As demonstrated previously, serum withdrawal in these cells induced cell death as shown by phosphatidyl serine exposure and propidium iodide labeling (Aouacheria et al., 2001). Nuclear changes typical of apoptosis were observed by Hoechst 33258 staining. As shown in Figure $4 \mathrm{~b}$, the appearance of pycnotic nuclei was largely prevented by the expression of $\mathrm{Nr}-13$ or Bcl-xL antiapoptotic proteins. Under these conditions, expression of the M2a2 aptamer that does not bind $\mathrm{Nr}-13 \mathrm{had}$ no effect, whereas M10b1 fully abolished the effect of $\mathrm{Nr}-13$, but not of Bcl-xL. Together, these data suggest that in both yeast and vertebrate, M10b1 is a potent antagonist of $\mathrm{Nr}-13$.

\section{Peptides corresponding to the variable region of the aptamers modulate $\mathrm{Nr}-13$ activity in a cell-free system} In the assays performed so far, variable regions of the peptide aptamers were conformationally constrained owing to their insertion into the TrxA expression platform. To determine whether the unconstrained 20 -mer variable regions alone would display the same a

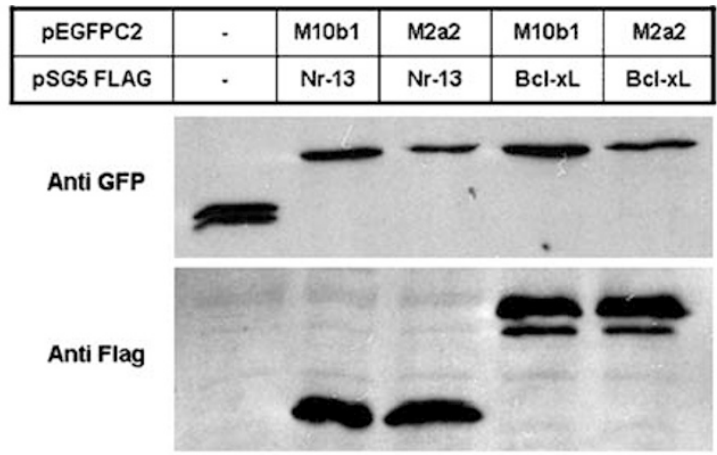

b

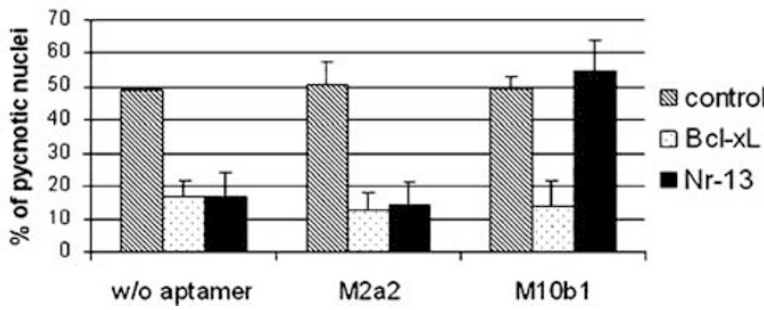

Figure 4 M10b1 aptamer specifically modulates Nr-13 activity in mammalian cells. COS-7 cells were transiently transfected to express $\mathrm{Nr}-13$ or Bcl-xL and the indicated aptamer, using pSG5FLAG and pEGFPC2 vectors, respectively. Expression of both aptamers and antiapoptotic proteins was verified by Western blotting $24 \mathrm{~h}$ post-transfection using anti-GFP and anti-FLAG antibodies, respectively (a). Vectors and expressed proteins are listed in the upper part of the figure; '- means that cells were transfected with empty vectors. (b) Assay for inhibitory effects of aptamers: transfected cells were serum starved for $48 \mathrm{~h}$. The percentage of pycnotic nuclei was determined using Hoechst 33258 staining. Histograms represent the mean value of three independent experiments. Standard error of the mean is shown. $\mathrm{Nr}-13$ and Bcl-xL efficiently inhibit cell death when co-transfected with either empty pEGFPC2 or the negative control pEGFPC2-M2a2. In contrast, $\mathrm{Nr}-13$ antideath activity is entirely suppressed by M10b1 aptamer co-expression, whereas Bcl-xL activity is not.

effects as the corresponding full-length aptamers, we synthesized the peptides corresponding to the variable regions of the two Nr-13-specific aptamers C6-14 and B16m3. Structure predictions using SOPMA software (Geourjon and Deléage, 1995) suggested an alphahelical conformation for these peptides. Circular dichroism analyses confirmed these predictions (not shown). We also synthesized the variable region of the B16m39negative control. We then tested the capacity of these three peptides to interfere with the activity of $\mathrm{Nr}-13$ using Xenopus egg extracts, in which caspases activate spontaneously. Caspase activity was detected via the cleavage of a specific substrate and subsequent fluorescence emission. We previously showed that the addition of purified $\mathrm{Nr}-13$ protein delays caspase activation in these extracts (Moradi-Améli et al., 2002). Addition of the synthetic peptides alone in this experiment does not significantly alter caspase activation. As expected, coincubation of the B16m39 peptide with $\mathrm{Nr}-13$ does not alter Nr-13 activity, whereas the addition of the C6-14 peptide together with $\mathrm{Nr}-13$ efficiently inhibits the anticaspase activity of $\mathrm{Nr}-13$, confirming the antagonistic effect of the C6-14 aptamer (Figure 5). This suggests 
that the C6-14 peptide can spontaneously adopt an active conformation and that the TrxA scaffold protein is dispensable. Interestingly, the $\mathrm{B} 16 \mathrm{~m} 3$ peptide was able to potentiate the activity of $\mathrm{Nr}-13$ in this assay. To confirm this unexpected effect, the experiment was carried out using different $\mathrm{B} 16 \mathrm{~m} 3 / \mathrm{Nr}-13$ ratios and time points. The results depicted in Figure $5 \mathrm{~b}$ confirm that $\mathrm{B} 16 \mathrm{~m} 3$ behaves as an agonist of $\mathrm{Nr}-13$ in a dosedependent manner.

Finally, to both explore the mode of action of B16m 3 and confirm this result with the entire aptamer, we tested if the B16m 3 aptamer was able to modulate Bax/ $\mathrm{Nr}-13$ interaction in a three-hybrid experiment. For this, we expressed in yeast a truncated Bax (amino acids 1-169) that does not induce yeast's death. We previously reported that $\mathrm{Nr}-13$ binds $\mathrm{Bax}$ via its $\mathrm{C}$ terminus part (amino acids 58-157), whereas its $\mathrm{N}$ terminus part

a

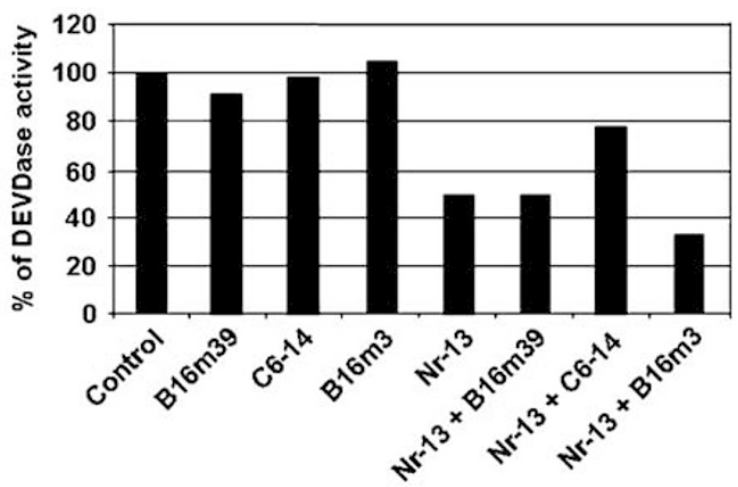

b

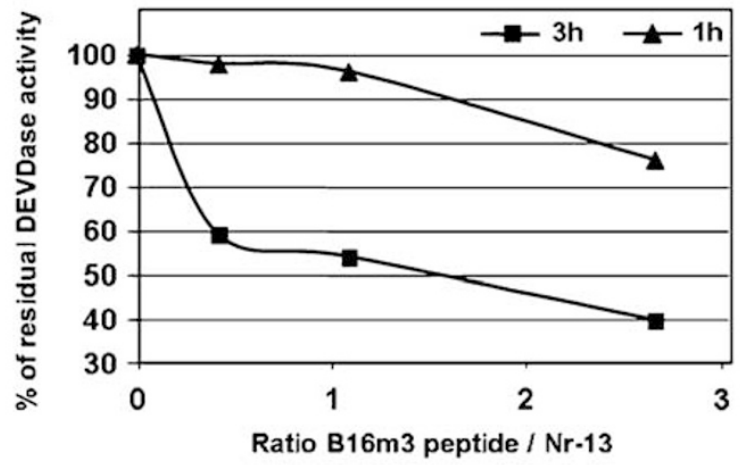

C

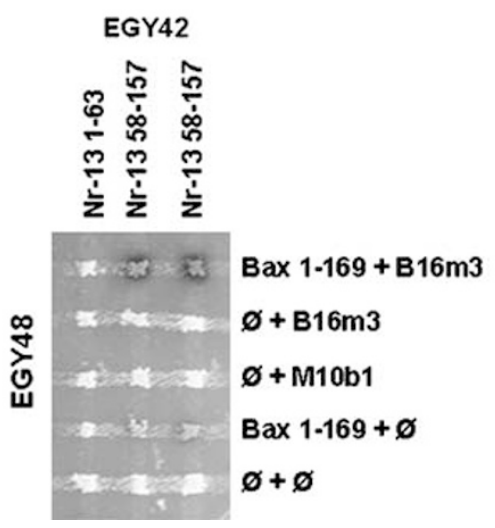

(amino acids 1-63) was unable to do so (Lalle et al., 2002). In Figure 5c, we show that a stronger Bax/Nr-13 interaction is detected using the $\beta$-galactosidase reporter when $\mathrm{B} 16 \mathrm{~m} 3$ is co-expressed in the same cells. This result suggests that $\mathrm{B} 16 \mathrm{~m} 3$ enhances or favors $\mathrm{Bax} / \mathrm{Nr}-13$ binding.

\section{Discussion}

The Bcl-2 family of proteins plays a major role in the control of apoptosis. The activity of the Bcl-2-like proteins is largely determined by their interactions with specific partners. Specific disruption of these interactions could be essential for studying and understanding the regulation of cell death at a molecular level, but also for the design of new drugs targeting the apoptosis machinery. In this study, we employed a variation of the yeast two-hybrid system to isolate one peptide aptamer (C6-14) selectively interacting with $\mathrm{Nr}-13$. A simultaneous screen against murine Bax allowed one to identify another aptamer (B16) able to bind both Bax and Nr-13. Such crossreactivity, although rarely reported, is not unique. Using the serine threonine kinase $\mathrm{Cdk} 2$ as bait, Colas et al. (1996) isolated a number of aptamers that also interacted with other Cdk family members. Not surprisingly, the $\mathrm{Nr}-13$ region recognized by $\mathrm{B} 16$ corresponds to the most conserved region between chicken Nr-13 and murine Bax. A set of additional aptamers with distinct specificities was obtained by random mutagenesis of C6-14 and B16 (Table 1). The apparent $K_{\mathrm{D}}$ values as determined by ELISA-based assay were 0.2 and $4.5 \mu \mathrm{M}$ for $\mathrm{B} 16 \mathrm{~m} 3$ and $\mathrm{M} 10 \mathrm{~b} 1$, respectively. The fact that $\mathrm{B} 16 \mathrm{~m} 3$ exhibits significantly higher affinity for $\mathrm{Nr}-13$ is not unexpected. Indeed, B16m3 may well interact with the hydrophobic cleft of

Figure 5 C6-14 linear peptide antagonizes $\mathrm{Nr}-13$ activity, whereas B $16 \mathrm{~m} 3$ peptide behaves as an activator. The activity of peptides derived from peptide aptamers was tested with an acellular assay. Xenopus egg extracts were incubated in the presence or absence of purified Nr-13 protein, with or without the indicated peptides. Kinetics of caspase activation was followed by monitoring the increase in the emission of fluorescence at $460 \mathrm{~nm}$ upon excitation at $380 \mathrm{~nm}$. The results shown in (a) correspond to a time point when $50 \%$ of caspase activity is inhibited by recombinant $\mathrm{Nr}-13$ protein. Under these conditions, the peptides alone have no significant effect. C6-14 peptide counteracts the inhibitory effect of $\mathrm{Nr}-13$ on caspase activation. In contrast, the $\mathrm{B} 16 \mathrm{~m} 3$ peptide enhances this inhibitory effect. The ratio of peptides to $\mathrm{Nr}-13$ is 1 in all cases. These data are representative of three independent experiments. Evaluation of the residual DEVDase activity was carried out using different $\mathrm{B} 16 \mathrm{~m} 3 / \mathrm{Nr}-13$ ratios (b), ranging from 0.42 to 2.66 , and different time points $(1$ and $3 \mathrm{~h}$ ). The effect of B $16 \mathrm{~m} 3$ on caspase activation is clearly dose-dependent. (c) To perform a mating assay, the EGY42 strain was co-transformed with pGILDA-Nr-13 and pSH18-34, whereas EGY48 was cotransformed with pJG4-5 (with or without Bax 1-169) and pBC103 expressing or not an aptamer. In this assay, Bax is able to bind only the $\mathrm{C}$ terminus part of $\mathrm{Nr}-13$. In the presence of the $\mathrm{B} 16 \mathrm{~m} 3$ aptamer that binds the $\mathrm{C}$ terminus part of $\mathrm{Nr}-13$, a stronger interaction is reported as shown by the dark blue color. ' $\varnothing$ ' means that cells were transformed with an empty vector. 
$\mathrm{Nr}-13$ (like BH3 peptides do) as it recognizes the $\mathrm{C}$ terminus half of Nr-13 (see Figure 1), encompassing this hydrophobic cleft. In contrast, M10b1 binds to the $\mathrm{N}$ terminus region of $\mathrm{Nr}-13$, encompassing the $\mathrm{BH} 4$ domain, which is devoid of such hydrophobic pocket, giving rise possibly to a less stable interaction.

In a yeast mating assay, the aptamers showed a highly specific interaction with $\mathrm{Nr}-13$ as shown by testing a collection of Bcl-2 family members, including both pro- and antiapoptotic proteins harboring a similar three-dimensional (3D) structure (Chou et al., 1999; McDonnell et al., 1999; Suzuki et al., 2000; Zhang et al., 2000; Petros et al., 2001; Lalle et al., 2002). Random mutagenesis of C6-14 allowed a derivative (M10b1) to be obtained with higher apparent affinity for $\mathrm{Nr}-13$. Co-immunoprecipitation experiments confirmed that the selected aptamers interacted directly with $\mathrm{Nr}-13$ and do not bind three other antiapoptotic Bcl-2 proteins, including the human Nr-13 ortholog Nrh (Figure 2a).

The ability of peptide aptamers to bind to $\mathrm{Nr}-13$ does not necessarily imply that they would have an effect on its activity. To assess this point, we first took advantage of our previous studies on $\mathrm{Nr}-13$ activity in yeast. Bax expression is lethal in yeast; this cytotoxic effect can be counteracted by several antiapoptotic proteins such as Bcl-xL, Bcl-2, Mcl-1, A1/Bfl-1, Nrh and Nr-13 (Hanada et al., 1995; Tao et al., 1997; Zhang et al., 2000; Aouacheria et al., 2001; Lalle et al., 2002). In this model, C6-14 and its derivative M10b1 partly inhibited Nr-13 activity, whereas B16m3 had no effect. Sequence alignment between C6-14 and M10b1 showed that the most severe change might have been the Leu to Met substitution at position 7 (Table 1). The higher efficacy of M10b1 might be owing to this mutation.

The most active $\mathrm{Nr}-13$ antagonist, M10b1, was further investigated in COS-7 mammalian cells. These cells are sensitive to serum withdrawal, showing typical chromatin condensation of apoptotic cells that is largely prevented by $\mathrm{Nr}-13$ and $\mathrm{Bcl}-\mathrm{xL}$ (this report), or $\mathrm{Nrh}$ (Aouacheria et al., 2001). We show here that the antideath effect of $\mathrm{Nr}-13$ is completely annihilated by M10b1, but not by another peptide aptamer unable to bind to $\mathrm{Nr}-13$. In the same assay, M10b1 is unable to modulate the Bcl-xL-protective effect. These results show that peptide aptamers directed against Bcl-2 family of apoptotic inhibitors may have proapoptotic properties.

We demonstrate here that peptide aptamers targeting an apoptotic inhibitor are actually functional in vertebrate cells. This is an important step toward the in vivo application of the peptide aptamer strategy. To our knowledge, the only in vivo study reported today was performed with anti-Cdk2 aptamers. These antihuman protein aptamers were also shown to inhibit related cell cycle regulators in Drosophila (Kolonin and Finley, 1998). Most of the other peptide aptamers that have been identified so far have not yet been tested in vivo probably because a prerequisite to their intracellular action is their delivery into cells. This could be a limiting step as largely shown for other gene therapy strategies. From this perspective, finding linear active peptides outside the context of the scaffold protein is of major interest. Several protein transduction domains have been developed over the past few years and used to transport various molecules into cells, including peptides (Wender et al., 2000). Success of these tools depends largely on the size of the product to transport, small peptides up to $20 \mathrm{kDa}$ being more efficiently transported.

Therefore, the description of peptides still active after removal from their scaffold is clearly a bonus when developing aptamer-derived drugs. To this aim, we decided to explore the functionality of the variable regions of C6-14 and B16m3. We chemically synthesized the two corresponding peptides and used them in an acellular caspase assay. The two peptides were found to be active in this assay: C6-14 behaves as a potent antagonist of $\mathrm{Nr}-13$, whereas $\mathrm{B} 16 \mathrm{~m} 3$ showed agonist properties (Figure 5a). This observation could explain the lack of effect of $\mathrm{B} 16 \mathrm{~m} 3$ shown in yeast: as $\mathrm{Nr}-13$ by itself fully restored the yeast exponentially growing phase (Lalle et al., 2002), a possible potentiation of $\mathrm{Nr}$ 13 effect by $\mathrm{B} 16 \mathrm{~m} 3$ could not be visualized in this assay.

Our data confirm previous reports describing that in some cases the variable regions of peptide aptamers are not dependent on the TrxA scaffold, suggesting that they could adopt a functional 3D structure on their own (Fabbrizio et al., 1999; Klevenz et al., 2002; Schmidt et al., 2002; Buerger et al., 2003; Kurtz et al., 2003). In contrast, other peptides show a drastic decrease in their efficiency outside the TrxA scaffold (Cohen et al., 1998; Klevenz et al., 2002).

This report is the first demonstration that apoptosis can be modulated by targeting a Bcl-2 family member with peptide aptamers. Among the three selected aptamers, two of them interact with the $\mathrm{N}$-terminal moiety of $\mathrm{Nr}-13$. This part of the protein encompasses the $\mathrm{BH} 4$ and $\mathrm{BH} 3$ domains. The $\mathrm{BH} 4$ domain is usually considered as a general feature of antiapoptotic proteins of the Bcl-2 family. Nevertheless, the definition of the $\mathrm{BH} 4$ domain is not as stringent as for the other Bcl-2 homology domains. Indeed, some apoptosis inhibitors may lack $\mathrm{BH} 4$, whereas a $\mathrm{BH} 4$ domain has been described in some apoptosis accelerators (Lanave et al., 2004). The BH4 domain corresponds to the most N-terminal amphipathic helix, which is supposed to stabilize the structure of the hydrophobic groove formed by the $\mathrm{BH} 3, \mathrm{BH} 1$ and $\mathrm{BH} 2$ domains, which serves as a receptor for $\mathrm{BH} 3$ amphipathic helices of proapoptotic proteins. A simple explanation for the antagonist effect of the aptamers in our assays is that they could prevent the $\mathrm{Nr}-13$ /Bax binding.

Recently, Cartron et al. (2005) reported that helix 1 of Bax could interact with $\mathrm{BH} 3$ via an electrostatic bond and that this interaction is essential to regulate Bax activation and addressing to mitochondria. As we described previously, a similar electrostatic interaction exists between the $\mathrm{BH} 4$ and $\mathrm{BH} 3$ domains of $\mathrm{Nr}-13$ that is able to modulate its antiapoptotic function, although the mechanism of this regulation is still unknown (Lalle et al., 2002). Interestingly, two peptide aptamers that we isolated are able to target the first 63 amino acids of 
Nr-13 encompassing the BH4 and $\mathrm{BH} 3$ domains. Therefore, these aptamers could be valuable tools for exploring the conformational changes occurring in this region of the protein, the regulation of its binding to Bax and its antiapoptotic activity.

The third aptamer that we isolated binds to the more conserved C-terminal part of $\mathrm{Nr}-13$. Surprisingly, it is able to potentiate its antiapoptotic activity. To our knowledge, this is the first aptamer to behave as an agonist. This is all the more surprising as all $\mathrm{Bcl}-2$ ligands described to date act as antagonists (Aouacheria et al., 2003). Thus, this aptamer could stabilize the $\mathrm{Nr}$ 13-active conformation and favor the formation of $\mathrm{Nr}$ 13 dimers or its association with proapoptotic partners. Indeed, as shown in Figure $5 \mathrm{c}, \mathrm{B} 16 \mathrm{~m} 3$ appears to increase $\mathrm{Nr}-13 / \mathrm{Bax}$ interaction in yeast, which may be owing to $\mathrm{Nr}-13$ stabilization. Interestingly, it has been recently reported that ligands that bind to the $\mathrm{C}$ terminus moiety of $\mathrm{A} 1$, a $\mathrm{Bcl}-2$ family member sharing homologies with $\mathrm{Nr}-13$, are able to increase the half-life of the A1 protein (Herold et al., 2006). Resolution of the 3D structure of $\mathrm{Nr}-13$-aptamer complexes will help to solve their precise mechanisms of action.

$\mathrm{Nr}-13$ displays several domains whose relative contributions to the function of the protein are not always understood. Developing inhibitors that target a precise domain represents an alternative strategy to the more classical knockout approach that affects the activity or the expression of the entire gene product. Here, we report such an inhibitor that is a potent and specific inhibitor of Nr-13 activity in live cells.

Finally, their small size and the knowledge of the TrxA scaffold 3D structure should help to elucidate the aptamer structure and to develop non-peptide mimetics with optimal efficiency. Such molecules would have important applications in basic research and cancer therapy. Future studies will focus on the efficiency of their in vivo delivery for therapeutic purposes. The present study could serve as a first step in the design of new anticancer molecules targeting Bcl-2 family members.

\section{Materials and methods}

Yeast strains and construction of two-hybrid plasmids EGY40 (MAT $\alpha$ leu2 his3 trp1 ura3), EGY42 (MATa leu2 his3 trp1 ura3) and EGY48 strains (MAT $\alpha$ his3 trp1 ura3-52 leu2:: LexA6op-LEU2) have been described previously (Gyuris et al., 1993; Estojak et al., 1995). Expressions of all fusion proteins in pEG202 and pGILDA were checked by Western blotting using an anti-LexA horseradish peroxidase (HRP) conjugate antibody (Santa Cruz Biotechnology, Santa Cruz, CA, USA, sc-7544, 1:100). To allow nuclear localization of $\mathrm{Bcl}-2$ proteins, C-terminal putative transmembrane domains were systematically removed. In all cases, subcloning of the coding sequences was performed between EcoRI and XhoI sites.

\section{Screening of the peptide aptamer library}

Aptamer screening was carried out in EGY48 as described previously (Colas et al., 1996). Briefly, as bait, the $\mathrm{N}$-terminal part of the Nr-13 protein, containing amino acids 1-63, was fused to the LexA protein into the pGILDA vector.
A randomized 20-mer peptide aptamer library in the pJM1 vector was used. EGY48 yeasts co-transformed with the bait construct and the library were selected for growth in the absence of uracil, histidine, tryptophan and leucine. Prey-bait interaction was verified by retransformation and interaction mating assay as described, using the pSH18-34 reporter plasmid (Finley and Brent, 1994).

\section{Random mutagenesis}

Variable regions of the $\mathrm{C} 6-14$ and $\mathrm{B} 16$ aptamers were amplified from the original library vectors following a mutagenic polymerase chain reaction protocol (Cadwell and Joyce, 1992). A pool of pJM-1 vectors harboring random mutations into the variable region were transformed into EGY48 containing pGILDA-Nr-13 1-63 or pGILDA-Bax and pRB18-40 (Estojak et al., 1995). Yeasts were plated on Ura His $^{-} \operatorname{Trp}^{-}$glucose. Transformants were replica plated onto $\mathrm{Ura}^{-} \mathrm{His}^{-} \mathrm{Trp}^{-}$glucose/XGal and $\mathrm{Ura}^{-} \mathrm{His}^{-} \mathrm{Trp}^{-}$galactose/ $\mathrm{XGal}$ plates. After 2 days at $30^{\circ} \mathrm{C}$, colonies that showed a blue color were transferred onto $\mathrm{Ura}^{-} \mathrm{His}^{-} \mathrm{Trp}^{-}$glucose plates. After a new replica plating onto $\mathrm{Ura}^{-} \mathrm{His}^{-} \mathrm{Trp}^{-}$glucose/XGal and $\mathrm{Ura}^{-} \mathrm{His}^{-} \mathrm{Trp}^{-}$galactose/XGal, colonies that still displayed intense blue color were selected. The aptamerencoding plasmids were recovered. After retransformation and mating, clones that still conferred an interaction phenotype were sequenced and used for further experiments.

\section{Yeast growth assays}

The EGY40 strain was co-transformed with pGILDA-Bax, pJG4-5 (Nr-13 or empty) and pBC103 (expressing or not an aptamer) (Sun et al., 1997). In these vectors, proteins are expressed under the control of the GAL1-inducible promoter. Selective medium containing $2 \%$ glucose was inoculated with a single colony of transformants and incubated overnight at $30^{\circ} \mathrm{C}$. Subsequently, cells were washed three times with water. Typically, $10 \mathrm{ml}$ of selective medium with $2 \%$ galactose was inoculated at optical density $(\mathrm{OD})_{600 \mathrm{~nm}}=0.1$. Growth was monitored for $60 \mathrm{~h}$. Samples were taken at different time points, and cell density was measured by determining the $\mathrm{OD}_{600 \mathrm{~nm}}$. Appropriate dilutions were performed regularly to maintain cells in an exponential growth phase.

\section{Three-hybrid experiment}

EGY42 was tranformed with pGILDA-Nr-13 and pSH18-34, whereas EGY48 was transformed by pJG4-5-Bax 1-169 and pBC103 (coding or not for an aptamer). Yeasts were mated as described previously (Finley and Brent, 1994).

\section{Production and purification of recombinant $\mathrm{Nr}$-13, peptide aptamers and $\operatorname{Tr} x A$}

The expression of recombinant $\mathrm{Nr}-13$ with an hexahistidine tag at its $\mathrm{C}$ terminus (Nr-13- $\Delta \mathrm{TM}-6 \mathrm{His})$ has been described previously (Moradi-Améli et al., 2002). Peptide aptamers and TrxA were produced as glutathione $S$ transferase (GST) fusion proteins; the GST moiety was removed by cleavage with thrombin. Peptide aptamer or TrxA cDNAs were subcloned into a GST expression vector (pGEX4T1, Amersham Biosciences, Orsay, France). The GST-fusion proteins were expressed in the BL21 E. coli strain, lysed in $20 \mathrm{mM}$ Tris $(\mathrm{pH}$ 7.5), $250 \mathrm{mM} \mathrm{NaCl}, 0.1 \%$ Triton $\mathrm{X}-100,5 \mathrm{mM}$ dithiothreitol (DTT), $1 \mathrm{mM}$ phenylmethylsulfonyl fluoride (PMSF), $1 \mathrm{~g} / 1$ lysozyme, $250 \mathrm{U} / \mathrm{ml}$ benzonase and a cocktail of protease inhibitors (Complete Mini, Roche Diagnostics, Meylan, France). Bacterial lysates were clarified by centrifugation for $30 \mathrm{~min}$ at 14000 r.p.m. and loaded onto a $1 \mathrm{ml}$ glutathione affinity column (GSTrap, Amersham Biosciences) equilibrated 
in Tris $20 \mathrm{mM}(\mathrm{pH} \mathrm{7.5)}$ and $\mathrm{NaCl} 150 \mathrm{~mm}$ buffer. The column was washed with 10 column volumes of equilibration buffer; then, $50 \mathrm{U}$ thrombin (Amersham Biosciences) re-suspended in cold phosphate-buffered saline (PBS) were loaded on the column that was then incubated for $16 \mathrm{~h}$ at $4^{\circ} \mathrm{C}$. The cleaved protein was eluted from the column with PBS and thrombin was eliminated through a para-aminobenzamidine affinity column (Amersham Biosciences). Eluted fractions were analysed by SDS-polyacrylamide gel electrophoresis (SDSPAGE) and those containing the wanted protein were pooled and dialysed overnight against $20 \mathrm{~mm}$ Tris (pH 8). The dialysate was then loaded onto an anion exchange column (Mono Q HR5/5, Amersham Biosciences) equilibrated in $20 \mathrm{~mm}$ Tris $(\mathrm{pH}$ 8) and proteins were eluted with a $\mathrm{NaCl}$ gradient $(100-500 \mathrm{mM})$. Eluted fractions were analysed by SDS-PAGE. Aptamer- or TrxA-containing fractions were pooled, concentrated and buffer exchanged using Vivaspin 4 devices with a $5 \mathrm{kDa}$ cutoff. Aptamer and TrxA concentrations were determined by both Bradford and $\mathrm{UV}_{280 \mathrm{~nm}}$ absorbance. Analysis of the different aptamers and TrxA was carried out by mass spectrometry (API 16S Sciex, Perkin-Elmer, Courtaboeuf, France) and secondary folding was checked by circular dichroism (Jobin Yvon CD6 spectropolarimeter).

\section{Co-immunoprecipitations}

COS-7 cells (African green monkey kidney cells) were maintained at $37^{\circ} \mathrm{C}, 5 \% \mathrm{CO}_{2}$ in Dulbecco's modified Eagle's medium (GIBCO) supplemented with $10 \%$ fetal bovine serum (Biowest, Nuailles, France), $1 \mathrm{mM}$ sodium pyruvate and penicillin/streptomycin (Biomedia, Boussens, France). Transfections were performed with pSG5-FLAG coding or not for a Bcl-2 family member using Fugene 6 reagent (Roche Diagnostics) according to the manufacturer's instructions. COS-7 lysates were prepared $24 \mathrm{~h}$ post-transfection by lysing in $20 \mathrm{mM}$ Tris ( $\mathrm{pH} 7.5), 150 \mathrm{mM} \mathrm{NaCl}, 1 \mathrm{mM}$ ethylenediaminetetraaceticacid, $1 \mathrm{mM}$ ethyleneglycoltetraacetate, $1 \%$ Triton X-100, $1 \mathrm{mM}$ PMSF and a cocktail of protease inhibitors. Lysate samples $(40 \mu \mathrm{g}$ protein) were mixed with $1 \mu \mathrm{g}$ of the purified aptamers (C6-14, M10b1 or M2a2) or TrxA devoid of the GST moiety. The volume was adjusted to $500 \mu \mathrm{l}$ with lysis buffer $(1 \%$ NP40, $0.5 \%$ sodium deoxycholate, $0.1 \%$ SDS and protease inhibitors) containing $0.1 \%$ Triton X-100 and $1 \mathrm{mM}$ DTT. The mix was then incubated for $1 \mathrm{~h}$ at room temperature. After the addition of $40 \mu \mathrm{l}$ of anti-FLAG antibody covalently linked to agarose beads (Sigma, SaintQuentin-Fallavier, France, A2220), samples were further incubated for $16 \mathrm{~h}$ at $4{ }^{\circ} \mathrm{C}$. After four washes in $50 \mathrm{mM}$ Tris ( $\mathrm{pH} 7.5), 150 \mathrm{mM} \mathrm{NaCl}$, immunocomplexes were re-suspended in $80 \mu \mathrm{l}$ of Laemmli buffer, boiled and $30 \mu \mathrm{l}$ were resolved on SDS-PAGE. After transfer onto nitrocellulose membrane (Hybond, Amersham), Bcl-2 proteins and aptamers were detected by using monoclonal anti-FLAG (Sigma, M2, 1:250) and polyclonal anti-TrxA antibodies (Santa Cruz, sc-801, 1:250), respectively. Detection was performed with anti-mouse HRP-conjugated immunoglobulin (Ig)G (DAKO, Trappes, France, 1:3000) or anti-rabbit HRP-conjugated IgG (DAKO, 1:2000), then chemoluminescent revelation (ECL, Amersham).

\section{Quantification of cell death}

COS-7 cells were co-transfected with pSG5-FLAG coding or not for a Bcl-2 family member and pEGFPC2 constructs coding or not for aptamers. To check the expression of proteins by SDS-PAGE, total cell lysates were prepared $24 \mathrm{~h}$ after transfection by lysing cells in 1\% NP40, 0.5\% sodium deoxycholate, $0.1 \%$ SDS and protease inhibitors. Samples
( $50 \mu \mathrm{g}$ protein) were loaded on gels, transferred onto nitrocellulose membrane and immunoblotted with anti-GFP polyclonal antibody (Invitrogen, Cergy-Pontoise, France, 1:5000) or anti-FLAG monoclonal antibody (Sigma, M2, 1:250, M2). Detection was performed using HRP-conjugated secondary antibodies and chemoluminescent detection. For quantification of cell death, cells were serum starved $8 \mathrm{~h}$ after transfection for $48 \mathrm{~h}$. Nuclei were then labeled with Hoechst 33258 fluorescent dye to detect pycnotic nuclei as described (Aouacheria et al., 2001). Three independent experiments were performed for each experimental point, with 100-250 GFPexpressing cells randomly counted in different areas.

\section{ELISA-style ligand binding assays}

Purified recombinant $\mathrm{Nr}-13-\Delta \mathrm{TM}-6 \mathrm{His}$ was diluted in $15 \mathrm{nM}$ $\mathrm{Na}_{2} \mathrm{CO}_{3}, 35 \mathrm{~mm} \mathrm{NaHCO}$ and $5 \mathrm{mM}$ DTT (pH 9.6), and coated at $600 \mathrm{nM}(1.1 \mu \mathrm{g} /$ well $)$ overnight at room temperature onto 96-well plates (Nunc, Wiesbaden, Germany). After washing with PBS, plates were blocked twice for $30 \mathrm{~min}$ with PBS and $2 \%$ bovine serum albumin (BSA) (Sigma). Various amounts of recombinant aptamers or TrxA protein dissolved in PBS $0.2 \%$ BSA $3 \mathrm{~mm}$ DTT were added for $50 \mathrm{~min}$. After extensive washing with PBS, $400 \mathrm{ng}$ of polyclonal anti-TrxA antibody (Santa Cruz, sc-801) were added in PBS $0.2 \%$ BSA for $35 \mathrm{~min}$ at room temperature. After three washing steps, $15 \mathrm{ng}$ of polyclonal goat anti-rabbit IgG-HRP conjugated (DAKO, P0448) were added in PBS $0.2 \%$ BSA for $30 \mathrm{~min}$. After three washes with PBS-Tween $200.01 \%$, plate-bound peroxidase was detected using 2,2'-azino-bis(3-ethylbenz-thiazoline-6-sulphonic) acid peroxidase substrate (Sigma, P1888) by measuring absorbance at $405 \mathrm{~nm}$. Apparent $K_{\mathrm{D}}$ was determined as described (Mann et al., 2004).

\section{Caspase inhibition assay in Xenopus egg extracts}

The caspase inhibition assay was originally designed to mimic the cleavage of poly(ADP-ribose) polymerase by caspase- 3 in the Xenopus egg extracts (Cosulich et al., 1997; Moradi-Améli et al., 2002). Caspase-3 activity was measured by assaying the cleavage of a fluorogenic peptide, Ac-DEVD-AMC, based on the known cleavage site of poly(ADP-ribose) polymerase $(\mathrm{DEVD} / \mathrm{G})$. Xenopus extracts were incubated in the presence or absence of $\mathrm{Nr}-13(20 \mu \mathrm{M})$ with or without B16m39, C6-14 or B16m3 peptides. Equimolar amounts of the peptide and $\mathrm{Nr}-13$ protein (peptide/Nr-13 ratio: 1) were used in all experiments, except for $\mathrm{B} 16 \mathrm{~m} 3$ (ratio from 0.42 to 2.66 depending on the experiments). All the peptides used in this assay were synthesized by the solid-phase method (Merrifield, 1964), purified by reverse-phase chromatography. Molecular masses were checked by mass spectrometry. For B16m3, only the first 19 amino acids of the variable region were synthesized.

\section{Acknowledgements}

We thank BB Rudkin for his initial support, N BonnefoyBérard for providing the $b f-1$ cDNA and D Ficheux for peptide synthesis. We also thank A Cornut for her skillful assistance in protein purification. We are grateful to $\mathrm{M}$ Moradi-Améli for her help and advice, and $\mathrm{T}$ Lorca for Xenopus extracts. This work was supported by the Association pour la Recherche sur le Cancer (ARC), the Ligue Nationale Contre le Cancer and the Région Rhône-Alpes. ALN was supported by the Fondation Mérieux and the ARC. ODL was supported by Retina France, and SV was supported by the ARC. 
Aouacheria A, Arnaud E, Venet S, Lalle P, Gouy M, Rigal D et al. (2001). Nrh, a human homologue of $\mathrm{Nr}-13$ associates with Bcl-Xs and is an inhibitor of apoptosis. Oncogene 20: 5846-5855.

Aouacheria A, Gillet G, Lalle P. (2003). Manipulating the Bcl-2 network. Experimental strategies and clinical applications. Recent Res Dev Mol Cell Biol 4: 59-84.

Aouacheria A, Ory S, Schmitt J-R, Rigal D, Jurdic P, Gillet G. (2002). p60(v-src) and serum control cell shape and apoptosis via distinct pathways in quail neuroretina cells. Oncogene 21: 1171-1186.

Buerger C, Nagel-Wolfrum K, Kunz C, Wittig I, Butz K, Hoppe-Seyler F et al. (2003). Sequence-specific peptide aptamers, interacting with the intracellular domain of the epidermal growth factor receptor, interfere with Stat3 activation and inhibit the growth of tumor cells. $J$ Biol Chem 278: 37610-37621.

Butz K, Denk C, Ullmann A, Scheffner M, Hoppe-Seyler F. (2000). Induction of apoptosis in human papillomavirus-positive cancer cells by peptide aptamers targeting the viral E6 oncoprotein. Proc Natl Acad Sci USA 97: 6693-6697.

Cadwell RC, Joyce GF. (1992). Randomization of genes by PCR mutagenesis. PCR Methods Appl 2: 28-33.

Cartron PF, Arokium H, Oliver L, Meflah K, Manon S, Vallette FM. (2005). Distinct domains control the addressing and the insertion of Bax into mitochondria. J Biol Chem 280: 10587-10598.

Chen L, Willis SN, Wei A, Smith BJ, Fletcher JI, Hinds MG et al. (2005). Differential targeting of prosurvival Bcl-2 proteins by their $\mathrm{BH} 3$-only ligands allows complementary apoptotic function. Mol Cell 17: 393-403.

Chou JJ, Li H, Salvesen GS, Yuan J, Wagner G. (1999). Solution structure of BID, an intracellular amplifier of apoptotic signaling. Cell 96: 615-624.

Cohen BA, Colas P, Brent R. (1998). An artificial cell-cycle inhibitor isolated from a combinatorial library. Proc Natl Acad Sci USA 95: 14272-14277.

Colas P, Cohen B, Jessen T, Grishina I, McCoy J, Brent R. (1996). Genetic selection of peptide aptamers that recognize and inhibit cyclin-dependent kinase 2. Nature 380: 548-550.

Cory S, Huang DC, Adams JM. (2003). The Bcl-2 family: roles in cell survival and oncogenesis. Oncogene 22: 8590-8607.

Cosulich SC, Worrall V, Hedge PJ, Green S, Clarke PR. (1997). Regulation of apoptosis by BH3 domains in a cell-free system. Curr Biol 7: 913-920.

Cotter FE, Waters J, Cunningham D. (1999). Human Bcl-2 antisense therapy for lymphomas. Biochim Biophys Acta 1489: 97-106.

Cui Q, Lim SK, Zhao B, Hoffmann FM. (2005). Selective inhibition of TGF- $\beta$ responsive genes by Smad-interacting peptide aptamers from FoxH1, Lef1 and CBP. Oncogene 24: 3864-3874

Degterev A, Lugovskoy A, Cardone M, Mulley B, Wagner G, Mitchison T et al. (2001). Identification of small-molecule inhibitors of interaction between the $\mathrm{BH} 3$ domain and $\mathrm{Bcl}$ xL. Nat Cell Biol 3: 173-182.

Estojak J, Brent R, Golemis EA. (1995). Correlation of twohybrid affinity data with in vitro measurements. Mol Cell Biol 15: 5820-5829.

Fabbrizio E, Le Cam L, Polanowska J, Kaczorek M, Lamb N, Brent $\mathrm{R}$ et al. (1999). Inhibition of mammalian cell proliferation by genetically selected peptide aptamers that functionally antagonize E2F activity. Oncogene 18: $4357-4363$
Finley Jr RL, Brent R. (1994). Interaction mating reveals binary and ternary connections between Drosophila cell cycle regulators. Proc Natl Acad Sci USA 91: 12980-12984.

Geourjon C, Deléage G. (1995). SOPMA: significant improvements in protein secondary structure prediction by consensus prediction from multiple alignments. Comput Appl Biosci 11: 681-684.

Girard-Egrot A, Chauvet J-P, Gillet G, Moradi-Améli M. (2004). Specific interaction of the antiapoptotic protein $\mathrm{Nr}$ 13 with phospholipid monolayers is prevented by the $\mathrm{BH} 3$ domain of Bax. J Mol Biol 335: 321-331.

Gyuris J, Golemis E, Chertkov H, Brent R. (1993). Cdil, a human $\mathrm{G} 1$ and $\mathrm{S}$ phase protein phosphatase that associates with Cdk2. Cell 75: 791-803.

Hanada M, Aimé-Sempé C, Sato T, Reed JC. (1995). Structure-function analysis of Bcl-2 protein. Identification of conserved domains important for homodimerization with Bcl-2 and heterodimerization with Bax. J Biol Chem 270: 11962-11969.

Hanahan D, Weinberg RA. (2000). The hallmarks of cancer. Cell 100: $57-70$.

Herold MJ, Zeitz J, Pelzer C, Kraus C, Peters A, Wohlleben G et al. (2006). The stability and anti-apoptotic function of Al are controlled by its C-terminus. J Biol Chem 281: 13663-13671.

Jiang X, Kim HE, Shu H, Zhao Y, Zhang H, Kofron $\mathrm{J}$ et al. (2003). Distinctive roles of PHAP proteins and prothymosinalpha in a death regulatory pathway. Science 299: 223-226.

Juin P, Geneste O, Raimbaud E, Hickman JA. (2004). Shooting at survivors: Bcl-2 family members as drug targets for cancer. Biochim Biophys Acta 1644: 251-260.

Klevenz B, Butz K, Hoppe-Seyler F. (2002). Peptide aptamers: exchange of the thioredoxin-A scaffold by alternative platform proteins and its influence on target protein binding. Cell Mol Life Sci 59: 1993-1998.

Kolonin MG, Finley Jr RL. (1998). Targeting cyclin-dependent kinases in Drosophila with peptide aptamers. Proc Natl Acad Sci USA 95: 14266-14271.

Kurtz SE, Esposito K, Tang W, Menzel R. (2003). Inhibition of an activated Ras protein with genetically selected peptide aptamers. Biotechnol Bioeng 82: 38-46.

Lalle P, Aouacheria A, Dumont-Miscopein A, Jambon M, Venet S, Bobichon $\mathrm{H}$ et al. (2002). Evidence for crucial electrostatic interactions between BCL-2 homology domains $\mathrm{BH} 3$ and $\mathrm{BH} 4$ in the anti-apoptotic NR-13 protein. Biochem J 368: 213-221.

Lanave C, Santamaria M, Saccone C. (2004). Comparative genomics: the evolutionary history of the Bcl-2 family. Gene 333: $71-79$.

Mangeney M, Schmitt JR, Leverrier Y, Thomas J, Marvel J, Brun G et al. (1996). The product of the v-src-inducible gene nr-13 is a potent anti-apoptotic factor. Oncogene 13: $1441-1446$

Mann HH, Ozbek S, Engel J, Paulsson M, Wagener R. (2004). Interactions between the cartilage oligomeric matrix protein and matrilins. Implications for matrix assembly and the pathogenesis of chondrodysplasias. J Biol Chem 279: 25294-25298.

McDonnell JM, Fushman D, Milliman CL, Korsmeyer SJ, Cowburn D. (1999). Solution structure of the proapoptotic molecule BID: a structural basis for apoptotic agonists and antagonists. Cell 96: 625-634.

Merrifield RB. (1964). Solid-phase peptide synthesis. 3. An improved synthesis of bradykinin. Biochemistry 14: $1385-1390$. 
Moradi-Améli M, Lorca T, Ficheux D, Di Pietro A, Gillet G. (2002). Interaction between the antiapoptotic protein $\mathrm{Nr}-13$ and cytochrome $c$. Antagonistic effect of the $\mathrm{BH} 3$ domain of Bax. Biochemistry 41: 8540-8550.

Nauenburg S, Zwerschke W, Jansen-Durr P. (2001). Induction of apoptosis in cervical carcinoma cells by peptide aptamers that bind to the HPV-16 E7 oncoprotein. FASEB J 15: 592-594.

Oltersdorf T, Elmore SW, Shoemaker AR, Armstrong RC, Augeri DJ, Belli BA et al. (2005). An inhibitor of Bcl-2 family proteins induces regression of solid tumours. Nature 435: 677-681.

Petros AM, Medek A, Nettesheim DG, Kim DH, Yoon HS, Swift K et al. (2001). Solution structure of the antiapoptotic protein bcl-2. Proc Natl Acad Sci USA 98: 3012-3017.

Pommier Y, Sordet O, Antony S, Hayward RL, Kohn KW. (2004). Apoptosis defects and chemotherapy resistance: molecular interaction maps and networks. Oncogene 23: 2934-2949.

Reed JC. (2003). Apoptosis-targeted therapies for cancer. Cancer Cell 3: 17-22.

Schmidt S, Diriong S, Mery J, Fabbrizio E, Debant A. (2002). Identification of the first Rho-GEF inhibitor, TRIPalpha, which targets the RhoA-specific GEF domain of Trio. FEBS Lett 523: 35-42.

Sun LJ, Peterson BR, Verdine GL. (1997). Dual role of the nuclear factor of activated $\mathrm{T}$ cells insert region in DNA recognition and cooperative contacts to activator protein 1 . Proc Natl Acad Sci USA 94: 4919-4924.

Suzuki M, Youle RJ, Tjandra N. (2000). Structure of Bax: coregulation of dimer formation and intracellular localization. Cell 103: 645-654.

Tao W, Kurschner C, Morgan JI. (1997). Modulation of cell death in yeast by the Bcl-2 family of proteins. $J$ Biol Chem 272: $15547-15552$.

Walensky LD, Kung AL, Escher I, Malia TJ, Barbuto S, Wright RD et al. (2004). Activation of apoptosis in vivo by a hydrocarbon-stapled BH3 helix. Science 305: 1466-1470.

Wang JL, Liu D, Zhang ZJ, Shan S, Han X, Srinivasula SM et al. (2000). Structure-based discovery of an organic compound that binds $\mathrm{Bcl}-2$ protein and induces apoptosis of tumor cells. Proc Natl Acad Sci USA 97: 7124-7129.

Wender PA, Mitchell DJ, Pattabiraman K, Pelkey ET, Steinman L, Rothbard JB. (2000). The design, synthesis, and evaluation of molecules that enable or enhance cellular uptake: peptoid molecular transporters. Proc Natl Acad Sci USA 97: 13003-13008.

Zhang H, Cowan-Jacob SW, Simonen M, Greenhalf W, Heim J, Meyhack B. (2000). Structural basis of BFL-1 for its interaction with Bax and its anti-apoptotic action in mammalian and yeast cells. J Biol Chem 275: 11092-11099. 